Acta Crystallographica Section E

Structure Reports

Online

ISSN 1600-5368

Editors: W. Clegg and D. G. Watson

\title{
Anhydrous guanidinium hydrogen fumarate: a two-dimensional hydrogen-bonded network structure
}

\author{
Graham Smith, Urs D. Wermuth, David J. Young and Peter C. Healy
}

Copyright $($ International Union of Crystallography

Author(s) of this paper may load this reprint on their own web site provided that this cover page is retained. Republication of this article or its storage in electronic databases or the like is not permitted without prior permission in writing from the IUCr. 
Acta Crystallographica Section E

Structure Reports

Online

ISSN 1600-5368

Graham Smith, ${ }^{\text {a* Urs D. }}$

Wermuth, ${ }^{a}$ David J. Young ${ }^{b}$ and

Peter C. Healy ${ }^{b}$

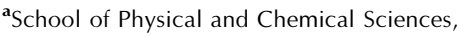
Queensland University of Technology, GPO Box 2434, Brisbane, Queensland 4001, Australia, and ${ }^{\mathbf{b}}$ School of Science, Griffith University, Nathan, Queensland 4111, Australia

Correspondence e-mail: g.smith@qut.edu.au

Key indicators

Single-crystal X-ray study

$T=297 \mathrm{~K}$

Mean $\sigma(\mathrm{C}-\mathrm{C})=0.002 \AA$

$R$ factor $=0.040$

$w R$ factor $=0.143$

Data-to-parameter ratio $=12.2$

For details of how these key indicators were automatically derived from the article, see http://journals.iucr.org/e.

\section{Anhydrous guanidinium hydrogen fumarate: a two-dimensional hydrogen-bonded network structure}

The title compound, $\mathrm{CH}_{6} \mathrm{~N}_{3}{ }^{+} \cdot \mathrm{C}_{4} \mathrm{H}_{3} \mathrm{O}_{4}{ }^{-}$, forms a two-dimensional hydrogen-bonded network structure. The guanidinium cations lie across crystallographic mirror planes while the hydrogen fumarate anions have inversion symmetry with the acid proton $50 \%$ disordered over the two carboxylate groups.

\section{Comment}

The known structures of guanidinium salts with diprotic aliphatic acids are not common and many are acid salts (Adams, 1978; Andrews et al., 1979; Leban \& Rupnik, 1992; Zyss et al., 1993; Krumbe et al., 1989; Krumbe \& Haussuehl, 1987; Golic et al., 1985; Froehlich et al., 1985).

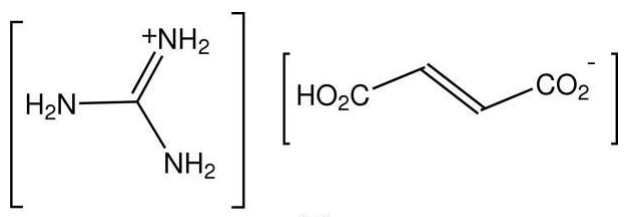

(I)

Since the incorporation of water molecules of hydration in guanidinium salts is dependent on the choice of solvent, we carried out the synthesis of (I) in $50 \%$ propan-2-ol-water to obtain the anhydrous 1:1 salt reported here. The centrosymmetric $P 2_{1} / \mathrm{m}$ model (rather than the $P 2_{1}$ model which was tried but gave poor refinement and low precision) places the guanidinium cation across a crystallographic mirror plane and the hydrogen fumarate anion across an inversion centre. This requires the single acid proton to be $50 \%$ disordered over the

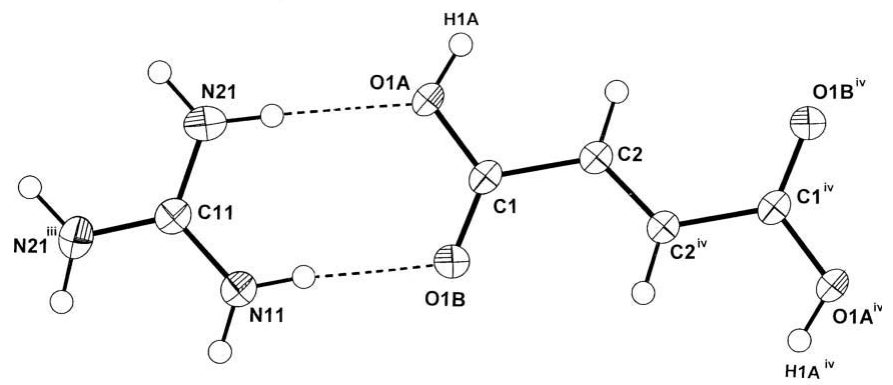

Figure 1

Molecular structure and atom-naming scheme for the guanidinium cation and the hydrogen fumarate anion in (I). Displacement ellipsoids are drawn at the $50 \%$ probability level. The guanidinium atoms N21 and $\mathrm{N} 21^{\mathrm{iii}}$ are related by mirror symmetry while the fumarate atoms designated (iv) are inversion-related [symmetry codes: (iii) $x,-y+\frac{1}{2}, z$; (iv) $-x,-y,-z+1]$. The fumarate acid protons $\mathrm{H} 1 A$ and $\mathrm{H} 1 A^{\text {iv }}$ are $50 \%$ disordered over the two carboxylate groups. Dashed lines indicate hydrogen bonds.
Received 7 December 2006 Accepted 22 December 2006 
two trans-related carboxylate groups (Fig. 1). All available proton donors and acceptors are involved in hydrogenbonding interactions (Table 1), giving a two-dimensional layered network structure (Fig. 2). For the guanidinium cation, there are six cyclic associations [two $R_{2}^{2}(8)$, two $R_{4}^{2}(10)$ and two $\left.R_{3}^{2}(11)\right]$. The two mirror-related 11 -membered rings are closed by single anti-related fumaric acid $\mathrm{H}$ atoms which also give intermolecular anti-associations with fumarate-O acceptors in strong $\mathrm{O} 1 A \cdots \mathrm{O} 1 A^{\mathrm{i}}$ hydrogen bonds (Table 1 ).

\section{Experimental}

The title compound was synthesized by heating together fumaric acid $(1 \mathrm{mmol})$ and guanidinium carbonate $(0.5 \mathrm{mmol})$ in $50 \mathrm{ml}$ of $50 \%$ propan-2-ol-water under reflux for $10 \mathrm{~min}$. After concentration to $c a$ $30 \mathrm{ml}$, partial room-temperature evaporation of the hot-filtered solution gave colourless crystal plates (m.p. 495-497 K).

\section{Crystal data}

$\mathrm{CH}_{6} \mathrm{~N}_{3}{ }^{+} \cdot \mathrm{C}_{4} \mathrm{H}_{3} \mathrm{O}_{4}^{-}$

$M_{r}=175.15$

Monoclinic, $P 2_{1} / m$

$a=5.4995(12) \AA$

$b=18.842(5) \AA$

$c=3.6943(11) \AA$

$\beta=94.83(2)^{\circ}$

$V=381.45(17) \AA^{3}$

\author{
$Z=2$ \\ $D_{x}=1.525 \mathrm{Mg} \mathrm{m}^{-3}$ \\ Mo $K \alpha$ radiation \\ $\mu=0.13 \mathrm{~mm}^{-1}$ \\ $T=297$ (2) K \\ Plate, colourless \\ $0.45 \times 0.32 \times 0.12 \mathrm{~mm}$
}

\section{Data collection}

Rigaku AFC-7R diffractometer $\omega-2 \theta$ scans

Absorption correction: none

1088 measured reflections

905 independent reflections

637 reflections with $I>2 \sigma(I)$

$$
\begin{aligned}
& R_{\text {int }}=0.025 \\
& \theta_{\max }=27.5^{\circ} \\
& 3 \text { standard reflections } \\
& \text { frequency: } 150 \mathrm{~min} \\
& \text { intensity decay: } 2.4 \%
\end{aligned}
$$

\section{Refinement}

Refinement on $F^{2}$

$R\left[F^{2}>2 \sigma\left(F^{2}\right)\right]=0.040$

$w R\left(F^{2}\right)=0.143$

$S=0.94$

905 reflections

74 parameters

$\mathrm{H}$ atoms treated by a mixture of

independent and constrained

refinement

\section{Table 1}

Hydrogen-bond geometry $\left(\AA,^{\circ}\right)$.

\begin{tabular}{lllll}
\hline$D-\mathrm{H} \cdots A$ & $D-\mathrm{H}$ & $\mathrm{H} \cdots A$ & $D \cdots A$ & $D-\mathrm{H} \cdots A$ \\
\hline $\mathrm{O} 1 A-\mathrm{H} 1 A \cdots \mathrm{O} 1 A^{\mathrm{i}}$ & $0.85(4)$ & $1.63(4)$ & $2.4658(18)$ & $166(5)$ \\
$\mathrm{N} 11-\mathrm{H} 11 \cdots \mathrm{O} 1 B$ & $0.88(3)$ & $1.99(3)$ & $2.873(2)$ & $174(2)$ \\
$\mathrm{N} 21-\mathrm{H} 21 A \cdots \mathrm{O} 1 B^{\mathrm{ii}}$ & $0.92(3)$ & $2.19(3)$ & $3.006(2)$ & $148(3)$ \\
$\mathrm{N} 21-\mathrm{H} 21 B \cdots \mathrm{O} 1 A$ & $0.89(3)$ & $2.10(3)$ & $2.991(2)$ & $175(3)$ \\
\hline
\end{tabular}

Symmetry codes: (i) $-x+1,-y,-z+2$; (ii) $x+1, y, z+1$.

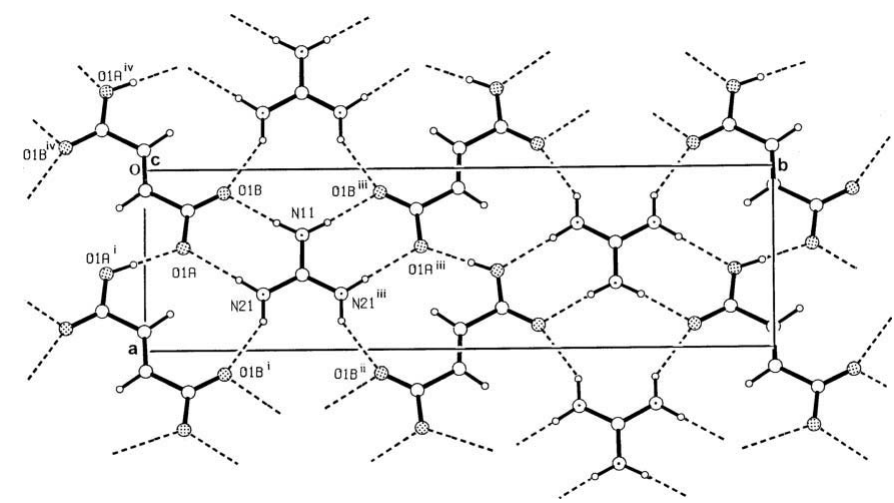

Figure 2

The hydrogen-bonded sheet structure of (I) viewed down the $c$ axial direction, showing hydrogen-bonding associations as dashed lines. For symmetry codes, see Fig. 1 caption and Table 1 .

The guanidinium $\mathrm{H}$ atoms and the fumarate acid $\mathrm{H}$ atom were located by difference methods and their positional and isotropic displacement parameters were refined. The fumarate ethylenic $\mathrm{H}$ atom was included in the refinement in a calculated position $(\mathrm{C}-\mathrm{H}=$ $0.94 \AA$ ) using a riding-model approximation, with $U_{\text {iso }}(\mathrm{H})=U_{\text {eq }}(\mathrm{C})$.

Data collection: MSC/AFC Diffractometer Control Software (Molecular Structure Corporation, 1999); cell refinement: $M S C / A F C$ Diffractometer Control Software; data reduction: TEXSAN for Windows (Molecular Structure Corporation, 1999); program(s) used to solve structure: SIR92 (Altomare et al., 1994); program(s) used to refine structure: SHELXL97 (Sheldrick, 1997); molecular graphics: PLATON (Spek, 2003); software used to prepare material for publication: PLATON.

The authors acknowledge financial support from the School of Physical and Chemical Sciences, Queensland University of Technology, and the School of Science, Griffith University.

\section{References}

Adams, J. M. (1978). Acta Cryst. B34, 1218-1220.

Altomare, A., Cascarano, G., Giacovazzo, C., Guagliardi, A., Burla, M. C., Polidori, G. \& Camalli, M. (1994). J. Appl. Cryst. 27, 435.

Andrews, L. C., Deroski, B. R. \& Ricci, J. S. (1979). J. Cryst. Mol. Struct. 9, 163 171.

Froehlich, R., Mattern, G. \& Krumbe, W. (1985). Z. Kristallogr. 172, 315-317. Golic, L., Leban, I., Detoni, S., Orel, B. \& Hadzi, D. (1985). J. Crystallogr. Spectrosc. Res. 15, 215-228.

Krumbe, W. \& Haussuehl, S. (1987). Z. Kristallogr. 179, 267-269.

Krumbe, W., Haussuehl, S. \& Froehlich, R. (1989). Z. Kristallogr. 187, 309-318. Leban, I. \& Rupnik, A. (1992). Acta Cryst. C48, 821-824.

Molecular Structure Corporation (1999). MSC/AFC Diffractometer Control Software and TEXSAN for Windows (Version 1.06). MSC, The Woodlands, Texas, USA.

Sheldrick, G. M. (1997). SHELXL97. University of Göttingen, Germany. Spek, A. L. (2003). J. Appl. Cryst. 36, 7-13.

Zyss, J., Pecaut, J., Levy, J. P. \& Masse, R. (1993). Acta Cryst. B49, 334-342. 